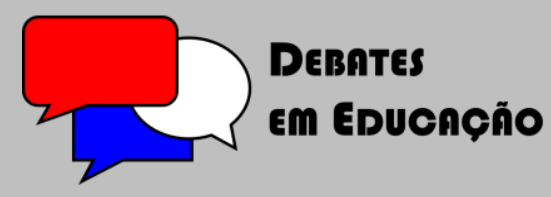

ISSN Eletrônico: 2175-6600

Vol. 10 | №. 20 | Jan./Abr. | Ano 2018

Elizeu Clementino de Souza

Universidade do Estado da Bahia (UNEB) esclementino@uol.com.br

Nanci Rodrigues Orrico

Universidade do Estado da Bahia (UNEB) Universidade Federal do Recôncavo da Bahia

nanciorrico@ufrb.edu.br

Hanilton Ribeiro de Souza

Universidade do Estado da Bahia (UNEB) hrsouza@uneb.br

\section{JUVENTUDES RURAIS, NARRATIVAS E RITO DE PASSAGEM: POR UMA EDUCAÇÃO PARA ALÉM DOS DITAMES DO MERCADO DE TRABALHO}

\section{RESUMO}

Este artigo propõe uma reflexão sobre questões que os estudantes de escolas rurais vivenciam no rito de passagem para a escola urbana, no que diz respeito, especialmente, aos seus anseios e expectativas sobre o mercado de trabalho e a sua inserção na sociedade contemporânea. O texto articula-se ao projeto de pesquisa e inovação educacional "Multisseriação e trabalho docente: diferenças, cotidiano escolar e ritos de passagem", que tem se dedicado a realizar estudos em torno do movimento ritualístico de ingresso de estudantes rurais em escolas urbanas. Nossas pesquisas indicam a necessidade de que a educação ofertada a estes jovens possa estar para além dos ditames do mercado de trabalho e mais vinculada às raízes identitárias destes sujeitos.

Palavras-chave: Juventudes rurais. Narrativas. Ensino Médio. Ruralidades. Mercado de trabalho.

\section{RURAL YOUTHS, NARRATIVES AND RITE OF PASSAGE: FOR AN EDUCATION FOR BESIDES THE DICTATES OF THE JOB MARKET}

\begin{abstract}
This article proposes a reflection on subjects that studentes of rural school live in the rite of passage to the urgan school, in what he says respect, especiallt, to their longings and expectations about the job Market and her insert the contemporary society. The text pronounces to the research Project and education innovation "Multigrade and educational work: differences, dialy school and rites of passage", that he has if dedicated to accomplish studies around the movement rite of rural students entrance in urban schools. Our researches indicate the need that the presented education the these youths can be for besides the dictates of the job Market and more linked to the roots identity of the subjects.
\end{abstract}

Keywords: Rural youths. Narrative. High school. Ruralities. Job market.

Submetido em: 28/01/2018

Aceito em: 28/04/2018

DOI: $10.28998 / 2175-6600.2018 v 10 n 20 p 64$ 


\section{PALAVRAS INICIAIS}

Intencionando propor uma reflexão sobre as juventudes rurais e os dilemas que vivenciam os jovens moradores de áreas rurais que, para dar continuidade aos seus estudos, precisam se deslocar para a cidade diariamente para estudar, este artigo traz à tona uma dinâmica vivenciada por um grande número de estudantes, porém que ainda tem sido escassamente pesquisada.

No quadro de pretensões anunciadas por esse estudo, salienta-se que se espera promover uma discussão sobre o rito de passagem ${ }^{1}$ escola rural/urbana que vivenciam os jovens e os conflitos e processos de exclusão, normatização e reconfiguração que experienciam estes estudantes com identidade rural ao ingressarem nas escolas urbanas. Também intencionamos refletir, especialmente, sobre como a escola nega os saberes e ruralidades de tais alunos e alunas, passando a funcionar como espaço de ensino de conteúdos descontextualizados, cerceamento e preparação dos jovens exclusivamente para o mercado de trabalho e para a convivência na sociedade contemporânea, com todas as suas demandas de consumo.

Ressaltamos que estes jovens moradores de áreas rurais chegam às escolas urbanas ávidos para viver novas experiências e conhecer novas pessoas e realidades, já que muitos só conhecem suas comunidades, entretanto, ao ingressarem na escola da cidade, veem-se excluídos, têm suas identidades negadas e começam a se modificar para se adequar a uma série de normas e padrões que não condizem com suas realidades e modos de ser e viver.

Essas observações têm sido constatadas no âmbito do projeto de pesquisa e inovação educacional "Multisseriação e trabalho docente: diferenças, cotidiano escolar e ritos de passagem"2, vinculado ao Grupo de Pesquisa (Auto)biografia, Formação e História

\footnotetext{
${ }^{1}$ As discussões sobre rito de passagem ancoram-se em ideias sistematizadas por Van Gennep (2008), ao conceber o rito como representação de uma transformação, a partir do qual o sujeito deixa de ser o que era para ser outra coisa em potência. Segundo o autor supracitado, durante o movimento ritualístico, o sujeito reflete sobre o seu papel no grupo social em que está inserido, repensando também os seus valores e questões morais, seguindo assim no processo de agregação de uma nova identidade. Para este autor, o rito se divide em três movimentos, a separação (que é o rito propriamente dito), a margem (o entre-rito e o imediatamente pós-rito, o liminar) e a agregação (a nova identidade pós-rito). Os ritos de passagem marcam, do ponto de vista simbólico, uma transição social, implicando novas disposições sobre a formação dos sujeitos ou modos de enfrentamento e negação por parte dos mesmos, evidenciados pelas marcas da passagem. (SOUZA et al, 2016).

${ }^{2}$ O projeto "Multisseriação e trabalho docente: diferenças, cotidiano escolar e ritos de passagem" conta com financiamento da Fundação de Amparo à Pesquisa do Estado da Bahia (FAPESB), no âmbito do Edital 028/2012 - Prática Pedagógicas Inovadoras em Escolas Públicas e do MCTI/CNPq, no âmbito da Chamada Universal $n^{0}$. 14/2014, sendo desenvolvido e coordenado pelo Grupo de Pesquisa (Auto)biografia, Formação e História Oral (GRAFHO/UNEB), sob supervisão do professor Elizeu Clementino de Souza, da Universidade do Estado da Bahia. Com o objetivo de desenvolver estudos sobre o cotidiano escolar e as condições de
} 
Oral (GRAFHO/UNEB), que vem realizado ações em diferentes municípios do território baiano com estudantes que vivenciam o rito de passagem escola rural/urbana e com os docentes que os acolhem.

Nossos estudos revelam a necessidade de uma maior discussão em torno das situações tematizadas, principalmente no que diz respeito ao fato de que o espaço escolar urbano vem negando as identidades dos alunos e alunas da roça, impondo para eles um modo de vida e anseios que vão de encontro às suas singularidades. Nessa perspectiva, iremos discutir, neste artigo, de forma articulada, temáticas como educação, juventudes rurais, ritos de passagem, normatização, modos de subjetivação e mercado de trabalho, de modo a evidenciar a necessidade de se construir, para os jovens da roça, uma escola mais acolhedora e uma educação mais emancipatória, que possa ir além da formação de mão de obra para o mercado de trabalho.

\section{JUVENTUDE, RURALIDADES E MODOS DE SUBJETIVAÇÃO: UM DEBATE NECESSÁRIO}

A intenção de publicizar e entrelaçar as nossas reflexões sobre juventude, trabalho, subjetividade, modos de subjetivação e educação em contextos rurais se potencializa a partir das discussões vivenciadas no âmbito do GRAFHO (Grupo de Pesquisa (Auto)biografia, Formação e História Oral), vinculado à Universidade do Estado da Bahia e também nas ações e formações da pesquisa "Multisseriação e trabalho docente: diferenças, cotidiano escolar e ritos de passagem"3. Este projeto de inovação educacional, do qual integramos a equipe de trabalho, surge com objetivos como o de minimizar processos de exclusão sofridos por estudantes de escolas rurais na passagem para a escola urbana e de elaborar materiais e propostas pedagógicas que acolham suas especificidades.

Reconhecemos a importância da discussão em torno dos processos de exclusão sofridos pelas populações rurais brasileiras, já que trazer à tona este tema exige, a priori, o entendimento de que historicamente estes sujeitos padecem com a falta de políticas

\footnotetext{
trabalho docente em classes multisseriadas e escolas rurais e urbanas que acolhem egressos de escolas rurais, tal projeto vem alcançado destaque ao realizar ações de inovação de práticas educacionais, como publicações de roteiros didáticos e cadernos temáticos de forma colaborativa entre professores da educação básica, de universidades, pesquisadores e estudantes de diferentes níveis de ensino (educação básica, graduação, pós-graduação). Duas teses de doutorado em desenvolvimento no PPGEduC/UNEB, vinculadas ao projeto guarda-chuva, as quais discutem diferentes questões, conflitos e situações vivenciados pelos jovens durante a transição da escola rural para a escola urbana.

${ }^{3} \mathrm{~A}$ referida pesquisa é financiada pela Fundação de Amparo à Pesquisa do Estado da Bahia (FAPESB), no âmbito do Edital 028/2012 - Práticas Pedagógicas Inovadoras em Escolas Públicas e do MCTI/CNPq, Chamada Universal $n^{0} .14 / 2014$.
} 
públicas que atendam aos seus interesses. Na área educacional, prevaleceu sempre o abandono, o que tem obrigado, desde muito tempo, os estudantes dessas áreas, a migrarem para a cidade, na busca de matrículas que lhes garantam a continuidade de seus estudos. Além disso, as escolas rurais têm sido marcadas pelo descaso, culminando na persistência dos altos índices de analfabetismo, de defasagem idade/série, de repetência e de evasão escolar com os quais os alunos/sujeitos da roça convivem desde sempre.

É certo que a busca por uma educação referenciada e representativa da singularidade dos povos rurais, para além da mera compensação aos direitos historicamente negados, ganhou força nas duas últimas décadas e a legislação, bem como as políticas públicas avançaram muito no sentido de contemplar as especificidades das escolas destas áreas (SOUZA, 2011). O movimento em prol de uma educação do campo de qualidade nasce na luta por uma educação "[...] forjada a partir da luta pela terra e por políticas públicas, empreendida pelos movimentos e organizações sociais do campo no Brasil [...]", como diz Munarim et al (2010, p. 10), e consegue feitos importantes.

Além da aprovação das Diretrizes Operacionais para a Educação Básica do Campo (RESOLUÇÃO CNE/CEB 1, 03/04/2002), outras conquistas podem ser citadas, dentre elas a criação da Secretaria de Educação Continuada Alfabetização, Diversidade e Inclusão (SECADI/MEC) em 2004, a promulgação do decreto no 7.352, de 4 de novembro de 2010, e também a elaboração do Programa Nacional de Educação do Campo (PRONACAMPO). É inegável que estes se tratam de avanços valiosos, porém muitas conquistas ainda precisam ser operacionalizadas, principalmente quando pensamos na expansão do Ensino Médio público no Brasil, especialmente nas cidades médias e pequenas e no ingresso de um grande contingente de alunos moradores de áreas rurais nas escolas urbanas. Sabemos que esse nível de ensino que era, originalmente, acessível, quando existia, apenas às elites locais, através de escolas particulares e/ou religiosas. A partir das últimas décadas do século XX, amplia-se sua oferta nos médios e pequenos municípios. Assim, ocorre, então, além do crescimento das matrículas neste nível educacional, o acesso de um novo público, mais popular e plural, às escolas secundárias, dentre eles os alunos e alunas egressos das escolas da roça.

É preciso destacar que consideramos ser de grande importância e legitimidade as pesquisas e os embates políticos e sociais no âmbito do Movimento Nacional da Educação do Campo, os quais propiciaram maior visibilidade às questões e aos problemas ligados à escola do campo e seus sujeitos, ocasionando, assim, mudanças nas leis, nas ações governamentais e, principalmente, impondo novas questões, debates e pesquisas sobre 0 tema nos meios acadêmicos. Porém, ressaltamos a opção teórica e política deste trabalho 
e do nosso grupo de pesquisa - GRAFHO -, pelos estudos relativos ao rural e as diversas ruralidades construídas e vivenciadas nesses territórios, que fundamentam a formação dos espaços, dos sujeitos e de sua percepção de si e de mundo. Dessa forma, nossos estudos tratam das ruralidades, aliando discussões sobre os sujeitos rurais, práticas escolares e os territórios, para, dessa forma, buscar compreender o processo de biografização dos sujeitos que residem, estudam e trabalham em áreas rurais (SOUZA, 2011; 2012).

As questões que nos propomos à reflexão, diante do exposto, são: O que vivenciam estes estudantes ao adentrarem nestes espaços educacionais? Será que a escola estava (e está) preparada para acolher e desenvolver atividades para um público tão diverso, especialmente respeitando as diferenças e as especificidades de cada indivíduo, seja ele da periferia da cidade ou da zona rural?

Podemos destacar, através das pesquisas até aqui empreendidas, que, na maioria das escolas urbanas que acolhem os estudantes rurais, essa não é uma realidade ainda contemplada. Dito de outra forma, não ocorre essa reflexão sobre a delicada teia da vida de cada estudante, não são respeitadas nem valorizadas as especificidades de cada ser; além disso, suas origens, expectativas e maneiras de ser e viver são invisibilizadas. Quando tal aluno é proveniente de uma comunidade rural, observa-se que tal invisibilidade é ampliada, sendo sua identidade suplantada para criação de uma identidade mais adequada à escola e à vida urbana, com todas suas demandas criadas para atender a sociedade urbana do consumo.

Percebe-se, então, que há uma espécie de "formatação" dos jovens que estudam nas escolas rurais quando vão para as escolas da cidade, à medida que suas características individuais vão sendo suplantadas e os estudantes vivenciam um verdadeiro processo de metamorfose no rito de passagem escola rural/escola urbana, modificando, inclusive, suas perspectivas de vida e expectativas de trabalho. Além dos intensos desafios de adaptação a uma nova rotina de deslocamento, de novas práticas pedagógicas, chamanos atenção a lógica da cultura urbana imposta a estes jovens. Nega-se a relação destes estudantes com o espaço, com a terra, com a natureza, com a comunidade, tornam-se invisíveis a sua cultura e a sua identidade rural nas práticas pedagógicas desenvolvidas na escola de Ensino Médio, evidenciando assim a modelagem deste indivíduo para a vida na sociedade urbana, num movimento de produção da subjetividade e bloqueio da singularização (GUATTARI; ROLNIK, 1996), já que, como ressaltam estes autores, "[...] os homens, reduzidos à condição de suporte de valor, assistem, atônitos, ao desmanchamento dos seus modos de vida. Passam então a se organizar segundo padrões universais, que os serializam $[\ldots] "$. 
Nesta perspectiva de normalização e nivelamento, Rios (2011a) também destaca que na escola as diferenças existentes nos sujeitos são tornadas invisíveis, tendo em vista o objetivo de normalização desses seres. Dessa forma, na tentativa de romper com tal processo normalizador e homogeneizador, é preciso discutir a escola enquanto espaço de homogeneização e o quanto o professor, com seus discursos e práticas, às vezes, sem perceber, participa, orienta e encaminha tal processo. Assim, entendemos, como Foucault (1997), a escola como um espaço da biopolítica, onde, através de discursos, práticas, simbologias e orientações (implícitas e explícitas), o biopoder altera as subjetividades dos sujeitos ali inseridos, normalizando-os. O que acontece, na ótica foucaultiana, é que:

[...] Para Foucault, a constituição do Estado moderno, com a gênese e o desenvolvimento das novas relações de produção capitalistas, leva à instauração da anátomo-política disciplinar e da biopolítica normativa enquanto procedimentos institucionais de modelagem do indivíduo e de gestão da coletividade; em outras palavras, de formatação do indivíduo e de administração da população [...]. (DANNER, 2010, p.144)

Sendo assim, é nossa intenção, neste trabalho, discutir o Ensino Médio e o processo de modelização e transformação de identidade cultural que os estudantes de escolas rurais vivenciam no rito de passagem para as escolas urbanas e a negação das suas especificidades e das suas maneiras de ser, viver e apreender o mundo para se adequar à identidade urbana, já que na cidade tudo é regulado e normatizado pelo e para o sistema hegemônico - o capitalista - e para seu objetivo principal, o lucro e acumulação. Reconhecemos, como afirmam Deleuze e Guattari (1995) e Guattari (1993), que o desenvolvimento desse processo de "produção da subjetividade capitalística", mais exacerbado nas áreas urbanas, é uma indústria pela qual se alimenta e se estrutura todo o sistema de base capitalista.

Além de ser extremamente relevante, essa discussão implica-nos na constatação de questões emergentes sobre este estudante que chega ao espaço escolar da cidade carregado de uma singularidade negada e visto a partir de uma ótica, temporalidade e representação negativas, pois como afirma Skliar, "[...] o tempo da modernidade e o tempo da escolarização insistem em ser, como decalques, temporalidades que só desejam a ordem, que teimam em classificar, em produzir mesmices homogêneas, íntegras, sem fissuras, a salvo de toda contaminação do outro [...]" (2003, p. 45).

Concordamos com Mésazáros (2005), que essa educação homogeneizadora é institucionalizada nas escolas, que passa a servir ao:

"[...] propósito de não só fornecer os conhecimentos e o pessoal necessário à maquinaria produtiva em expansão do sistema capitalista, mas também o de gerar 
e transmitir um quadro de valores que legitima os interesses dominantes, [...]." (MÉSAZÁROS, 2005, p. 112).

Nessa perspectiva, esperamos, a partir deste estudo, tornar visíveis questões sobre territorialidade, pertencimento, identidade cultural, modos de subjetivação e biopolítica na tentativa de, lançando novos olhares e entrelaçando diferentes problemáticas, buscarmos elementos que possam apontar novos caminhos a serem trilhados pelos profissionais da educação que acolhem estes jovens rurais no ingresso deles nas escolas urbanas, ratificando nossa luta por uma educação emancipatória, para além de atender os imperativos do mercado de trabalho.

\section{PESQUISA (AUTO)BIOGRÁFICA: NARRATIVAS DOS JOVENS RURAIS}

Segundo Josso (2010, p. 139), a expressão "caminhar para si" é palavra chave da sua existência, pois, para a autora, esta frase "[...] é um verdadeiro pilar para mim, porque me permite (re)questionar regularmente o rumo da minha vida e se continuo a navegar [...]". Sendo assim, propomos refletir sobre a potencialidade dos estudos que se ancoram metodologicamente na pesquisa (auto)biográfica tanto para os jovens rurais que ingressam nas escolas urbanas quanto para os demais atores envolvidos nesse processo, professores, pesquisadores, comunidade escolar e família, à medida que os estudos com base metodológica (auto)biográfica promovem um "caminhar para si".

Os jovens moradores de áreas rurais têm sido historicamente excluídos das políticas públicas e, na dinâmica educacional, são invisibilizados. Suas ruralidades e formas de ser e viver têm sido negadas nas práticas pedagógicas e nos materiais didáticos. A intenção desse estudo perpassa, então, pelo desejo de escuta acerca do que experienciam estes estudantes ao vivenciarem o rito de passagem escola rural/escola urbana e, a partir das suas narrativas, apreender como lidam com os desafios inerentes a esse processo de ir e vir diário, de ser e não ser da roça, das mudanças geográficas, educacionais, culturais e identitárias vividas.

Apostamos na pesquisa (auto)biográfica com os jovens, acreditando no potencial investigativo da (auto)biografia, em função da fertilidade da metodologia utilizada como dispositivo de reflexividade biográfica, já que quem se narra, se descobre, se conhece, se ressignifica, entendendo que narrar-se é matéria-prima para a construção da ponte que permite ao sujeito fazer a travessia de si, travessia essa que lhe dá o poder, como diria Manoel de Barros (1996, p. 75) "[...] de transver o mundo [...]”, ou seja, de ver além, de nós 
e dos nós que nos atam às questões históricas e materiais que compõem a nossa existência.

No contexto pouco estudado de estudantes que se deslocam de áreas rurais para estudar em áreas urbanas, (auto)biografar-se permite-nos o entendimento também dos processos de reconfiguração, normatização e conflitos que vivenciam os jovens, além da visualização de novos caminhos educacionais para os estudantes egressos de escolas rurais de modo que a educação ofertada para estes alunos e alunas possa romper com a lógica urbanocêntrica que ainda impera nestas escolas.

Como aponta Souza (2014):

[...] No campo educacional brasileiro, as pesquisas (auto)biográficas tem se consolidado como perspectiva de pesquisa e como práticas de formação, tendo em vista a oportunidade que remete tanto para pesquisadores, quanto para sujeitos em processo de formação narrarem suas experiências e explicitarem, através de suas narrativas orais e/ou escritas, diferentes marcas que possibilitam construções de identidades pessoais e coletivas [...]. (SOUZA, 2014, p. 40)

Ratificamos, então, a utilização das entrevistas narrativas com os jovens colaboradores pelas oportunidades que remetem e por acreditarmos no seu potencial investigativo e formativo, já que entendemos que a pesquisa (auto)biográfica vem promovendo, desde as primeiras décadas do século $\mathrm{XX}$, uma ruptura nos métodos convencionais de investigação, colocando a subjetividade como articuladora de novas formulações teóricas que realimentam diversas áreas.

O crescimento dos estudos a partir das abordagens experienciais no Brasil tem se intensificado nas últimas décadas, justamente com o fortalecimento do pensamento pedagógico crítico e das ações políticas e lutas sociais demandadas por movimentos de setores organizados da sociedade civil identificados com a construção de uma sociedade igualitária e de respeito à diversidade cultural brasileira.

Neste ensejo, ocorre, como aponta Bueno (2002), a grande virada metodológica em torno das pesquisas educacionais a partir dos anos 80 (NÓVOA e FINGER, 2014), quando Nóvoa (1992) propõe uma nova direção para os estudos sobre formação docente, numa perspectiva mais subjetiva. É importante marcar que, nesse período, as discussões em torno da relevância do ator social nas pesquisas educacionais eclodiam, motivadas pelo contexto mundial de transformações socioeconômicas e de mudanças paradigmáticas nas ciências humanas, o que favoreceram sobremaneira "as pesquisas que exploravam aspectos da subjetividade do professor e as novas formas de demarcar o espaço simbólico". (PASSEGGl et al, 2006, p. 259) 
Com um campo de pesquisa crescente no Brasil, a investigação (auto)biográfica tem se consolidado pela fertilidade em vincular biografia e educação e especialmente pela sua potencialidade e diversidade de formas e modos de aprender a vida.

[...] Essa diversidade vem ampliando princípios teórico-metodológicos para apreender dimensões de formação, condições de trabalho e formação, aspectos relacionados à história da profissão, tendo em vista as fertilidades que vinculam biografia e educação [...] (PASSEGGI, SOUZA, VICENTINI, 2011, p. 382).

Nesse estudo, fazemos a opção pelas entrevistas narrativas como dispositivo de pesquisa, pois, conforme sinaliza Souza (2010), os métodos de recolha de dados na pesquisa (auto)biográfica são múltiplos e dependem da pertinência para o objeto de estudo e interesses do pesquisador. A opção pela entrevista narrativa se dá também pela consciência do potencial que este instrumento tem como viabilizador de novas construções identitárias, tendo em vista que tal método possibilita a busca de significados das experiências de vida dos sujeitos, enquanto seres únicos, ao mesmo tempo em que também proporciona que os sujeitos se conheçam melhor, num processo de formação considerada como um processo tripolar, pilotado por três polos principais: si (autoformação), os outros (heteroformação) e as coisas (ecoformação) ${ }^{4}$. (PINEAU, 2000).

Segundo Jovchelovitch e Bauer (2010, p. 91), através das narrativas, o que acontece é que "[...] as pessoas lembram o que aconteceu, colocam a experiência em uma sequência, encontram possíveis explicações para isso, e jogam com a cadeia de acontecimentos que constroem a vida individual e social [...]". Também Bosi (2007), pontua que a lembrança é muito mais do que apenas reviver, mas, acima de tudo, é refazer, reconstruir, repensar, com ideias e imagens de hoje, as experiências do passado, entendendo a memória não como sonho, mas como trabalho e ressignificação das experiências vividas. As entrevistas narrativas como instrumento de liberdade e de reconstrução do sujeito possibilitam que, ao (re)contar um momento da vida, ele refaça e reconstrua os fatos que experimentou, não como eles aconteceram, mas com os subsídios e materiais simbólicos que o hoje lhe oferece, que agora lhe estão disponíveis.

Em outras palavras, acreditamos que, ao contar suas histórias e o que têm vivenciado no rito de passagem escola rural/urbana, os jovens possam pensar, elaborar e reelaborar suas experiências, conflitos e anseios, refletindo sobre as situações vividas e nos permitindo, enquanto pesquisadores, a apreensão, de modo não invasivo, das suas

\footnotetext{
${ }^{4}$ Em linhas gerais, segundo Pineau (2000), os processos formativos podem acontecer de três maneiras, que são: a autoformação, a heteroformação e a ecoformação. Na heteroformação, a formação advém da influência do outro, já a ecoformação é concebida através da interação do sujeito com o meio e, por fim, entende-se a autoformação como uma intermediária da ecoformação e da heteroformação juntas, na qual, através da retrospectiva dos atos e ações, o sujeito ressignifica sua prática e formação.
} 
histórias, dilemas e vivências na dinâmica de ser um estudante com identidade rural inserido em uma escola pensada em padrões urbanos.

\section{ENSINO MÉDIO, RITOS DE PASSAGEM E MERCADO DE TRABALHO: COM A PALAVRA, OS JOVENS MORADORES DE ÁREAS RURAIS}

Temos apreendido, a partir dos diálogos com os estudos de Santos e Souza (2014), Souza (2011; 2008), Antunes-Rocha e Hage (2010), Damasceno e Beserra (2004) e Amiguinho (2008; 2003), que a indicação e a predominância histórica da lógica da prática educativa pautada na transferência do modelo urbano adotado pela escola da cidade nas escolas rurais e nas escolas que acolhem alunos vindo destes espaços vem reforçando, para estes sujeitos, a visão de que o rural se configura como inferior, atrasado e inadequado.

No que diz respeito aos jovens estudantes do Ensino Médio que vivem em áreas rurais, mas deslocam-se diariamente para estudar na cidade, percebemos que, apesar das tentativas de reformulação do Ensino Médio, desde a implantação da LDB 9394/1996, ainda observamos que muito ainda resta para que a escola se aproxime do aluno (seja na questão profissional, social ou pessoal) e do seu cotidiano, valorizando-os. Os Parâmetros Curriculares para o Ensino Médio, já enfatizavam tal necessidade: "Na escola atual, as perspectivas profissionais, sociais ou pessoais dos alunos não têm feito parte das preocupações escolares, assim como as questões e problemas da comunidade, da cidade, do país ou do mundo só têm recebido atenção marginal" (BRASIL, 2002, p. 9-10).

Os Parâmetros Curriculares Nacionais do Ensino Médio também destacam a importância da valorização das diferenças, a fim de evitar o nivelamento ou a normalização (FOUCAULT, 1997) dos indivíduos/alunos, processo tão comum em nossas escolas e sociedade.

[...] As escolas devem estar conscientes de que devem promover todos os seus alunos e não selecionar alguns; que devem emancipá-los para a participação e não domesticá-los para a obediência; que devem valorizá-los em suas diferenças individuais e não nivelá-los por baixo ou pela média [...]. (BRASIL, 2002, p.13)

Assim, na busca pela superação dos desrespeitos, da não valorização e da invisibilidade quanto às especificidades do outro, especialmente dos estudantes que vivem em áreas campesinas, é que a escola e seus professores necessitam repensar a sua prática pedagógica, buscando perceber, valorizar e aprender a utilizar tais singularidades 
para a produção do conhecimento, a fim de não comprometer a formação e o futuro do estudante, bem como o desenvolvimento do lugar, tendo em vista que este processo depende da educação plena, reflexiva e cidadã, que deve ser fornecida pela escola para seus alunos e alunos, tão diversos e singulares ao mesmo tempo.

Entendemos que, tendo em vista as questões levantadas até então, torna-se necessário promover a escuta dos jovens que vivenciam o processo supracitado, na tentativa de acolher e apreender como eles se veem e se percebem neste processo. Nesta perspectiva, propomos um olhar para o que temos chamado de rito de passagem escola rural/urbana, ratificando nosso entendimento de que o rito se constitui um processo dialético-social que (inter)media a relação caos e ordem. Diferentes situações ritualísticas são vivenciadas no âmbito escolar: a chegada, a hora do lanche, da prova, da saída, sendo ainda que estes ritos podem ser de ordem, de atividade, de passagem e até de identidade. Van Gennep (2008) salienta que a escola opera na condição de promotora da ordem e obediência ao projeto social através das dinâmicas ritualísticas que impõe aos estudantes e demais membros da comunidade escolar.

O rito de passagem que nos instiga enquanto pesquisadores é um rito iniciático, pois o fato de sair da própria comunidade rural para iniciar seus estudos em uma escola urbana imprime sobre o sujeito uma marca simbólica, impondo também uma linguagem, ou seja, o sujeito informa por intermédio do signo sua agregação àquela identidade e a separação da identidade pretérita. Entendemos o ambiente escolar como importante espaço de consolidação das marcas identitárias de uma sociedade, e, sendo os ritos de passagem, situações liminares nas quais o sujeito se agrega a um novo horizonte, a escola tem papel fundamental na difusão e instituição dos ritos como marca formativa. Daí a importância de pensar os ritos de passagem de estudantes de escolas multisseriadas rurais para escolas seriadas da cidade a partir da escuta dos estudantes que vivenciam este rito. Para isso, optamos pela realização de entrevistas narrativas (SCHUTZE, 2010) com um grupo de alunos do Ensino Médio do Colégio Estadual Polivalente de Castro Alves - Castro Alves/BA, município do Recôncavo baiano. Destacamos que tal escola é a única a ofertar - Ensino Médio nesta cidade, possuindo um percentual de cerca de $42 \%$ de alunos provenientes da zona rural, segundo informações da Secretaria Escolar da referida escola.

A opção pelo uso das entrevistas narrativas como dispositivos de pesquisa está baseada na importância que concebemos à escuta dos sujeitos e ao método (auto)biográfico, tendo em vista que tal método possibilita a busca de significados das experiências de vida do sujeito. Nessa perspectiva investigativa, tais entrevistas servem para que promovamos um diálogo com jovens rurais numa escola urbana sobre suas 
expectativas, anseios e vivências para o futuro, especialmente quais suas perspectivas de inserção na sociedade e no mercado de trabalho. Esclarecemos que, por conta do compromisso ético de não identificação do entrevistado, os nomes utilizados serão fictícios: Maria, Raquel, João e Elias. Os alunos e alunas colaboradores são estudantes do $3^{\circ}$ ano do Ensino Médio da escola supracitada, e possuem entre 17 e 18 anos. Eles se prontificaram, quando consultados e esclarecidos quanto aos objetivos, a contribuir com tal trabalho de forma generosa e conscienciosa sobre a necessidade de que esse tema seja mais estudado.

Salienta-se que todos os colaboradores estudaram em classes multisseriadas durante os Anos Iniciais do Ensino Fundamental, passando a estudar na cidade a partir dos Anos Finais do Ensino Fundamental. Agora estão concluindo o Ensino Médio (2015). Dessa forma, sabemos que a escola como espaço de vida, de experiência e também de dispositivos do biopoder, já deve ter fornecido inúmeros subsídios para a (re)construção de suas identidades e das representações da realidade, suplantando e/ou até negando as suas ruralidades. Nesse sentido, Delory-Momberger (2012, p. 192), nos diz: “[...] para aqueles que o frequentam, o 'mundo da escola' constitui um espaço de vida e de experiência particular, na medida em que ele envolve instituições e contextos, procedimentos e dispositivos, papéis e relações sociais, tarefas e objetos específicos [...]".

Neste ensejo, tal trabalho, utilizando-se das narrativas, vem discutir as expectativas de vida destes alunos que vivem no campo, mas cursam o Ensino Médio nas escolas da cidade. Assim, analisemos, então, tal processo através dos relatos dos estudantes colaboradores:

[...] Hoje quero ser psicóloga, mas antes queria ser veterinária, mas quando passei a conhecer melhor as coisas descobri essa paixão pela Psicologia. É claro que estudar na cidade contribuiu para isso, pois tive conhecimento de outras profissões. Sei que veterinário é uma profissão importante também, mas na zona rural ninguém valoriza veterinário não, pois cada um cuida do seu bicho do seu jeito e não vai pagar a veterinário não [...]. (RAQUEL, 2015)

[...] A vinda para estudar na cidade fez com que mudasse muitas coisas, pois conhecemos outras oportunidades e passei a perceber que algumas profissões são mais valorizadas que outras [...]. (MARIA, 2015)

[...] Quero ser policial ou até engenheiro agrônomo, mas não quero ser trabalhador rural não. Sei que é um trabalho honesto, mas não quero essa vida não. Quero outra vida [...]. (JOÃO, 2015)

Notamos nos relatos dos alunos que, apesar da forte ligação com o ambiente rural, com o espaço que vivem, suas expectativas giram em torno de experimentação de outras vivências e experiências de trabalho fora do ambiente rural, à medida que a cidade, através da força de sedução, exerce papel fundamental nesse processo. Além do mais, na 
sociedade contemporânea, ainda prevalece a dicotomia entre o urbano e o rural, onde este último, tido como selvagem, rústico, tradicional e incivilizado, deve ser suplantado pelo primeiro. Dessa forma, os sujeitos rurais, apesar de gostarem do lugar onde residem, buscam outros espaços e vivencias para satisfazer suas necessidades, bem como para assumir a identidade imposta pela sociedade urbana e industrial. Nesse sentido, Tuan (1983, p.3) destaca que "[...] o lugar é segurança e o espaço é liberdade: estamos ligados ao primeiro e desejamos o outro [...]".

Ao serem questionados se pretendem, depois de concluir os estudos, retornar para morar no campo, contribuindo assim para o desenvolvimento das suas comunidades, os jovens dizem que:

[...] Nenhum jovem quer ficar na zona rural não, pois é desvalorizado a vida e o trabalho. [...] penso assim, fazer um curso e retornar para ajudar meus pais. Retornar para morar não, mas para ajudar eles [...]. (MARIA, 2015)

[...] Na minha comunidade não tem muitos jovens não, todos já saíram. Eu falo para minha mãe e meu pai, quando for embora para morar ou estudar na cidade, vou levar eles juntos ou quem sabe, quando estiver bem de vida, vou ajudar eles para que não fiquem só precisando da roça não [...]. (RAQUEL, 2015)

[...] Queria ser veterinário, mudei porque passei a gostar de outra profissão, e cortando cabelo, como cabeleireiro, posso continuar vivendo na zona rural ou até aqui na cidade também. Lá eu já tenho meus clientes. O trabalho na roça não rende não. Meu pai plantou maracujá, mas não pode continuar produzindo, pois ficou caro pagar pela água para irrigar. Lá quem tem uma vida um pouco melhor é quem tem lavoura e tem outro emprego, como professor de escola [...]. (ELIAS, 2015)

Observamos nos relatos dos estudantes o quanto eles vão se transformando, adquirindo novas formas de pensar mais de acordo com a lógica urbanocêntrica, com os ditames de consumo e da necessidade de estar bem financeiramente: "quando estiver bem de vida..." (Raquel, 2015), passando a idealizarem uma vida na cidade. Rios sinaliza que neste rito de passagem escola rural/urbana o aluno "[...] passa pela construção do desconhecido, do imprevisível, do incontrolável, da ausência da 'mesmidade', os quais compõem as relações com o outro, colocando a fronteira que o identifica à prova; atravessar, cruzar as fronteiras significa assumir posições híbridas [...]” (2011b, p.109). Nota-se o processo de subjetivação destes sujeitos, realizado pela sociedade e pela escola urbana, onde suas identidades rurais são negadas e anuladas para a formação de uma identidade urbana. Tal processo também implica na desvalorização do trabalho e vida rurais, contribuindo de forma decisiva para o êxodo rural e suas consequências, tendo em vista a migração dos jovens rurais para as cidades.

[...] Quando mudei para cá, para a escola da cidade, foi difícil, pois a gente já tava acostumado com um professor tipo familiar, e aí passamos a conhecer mais pessoas. Era estranho [...]. (ELIAS, 2015) 
[...] Lá eu conhecia a professora e os colegas desde menorzinho, a gente já tinha intimidade e a convivência era mais fácil, aqui a gente não conhecia ninguém e se sentia assim meio desconfortável [...]. (JOÃO, 2015)

João e Elias também enfatizam essa ausência da "mesmidade", mas já trazem também a questão de estar e conviver com o outro, aqueles que não são conhecidos e familiares, como ocorria na escola rural. A escola urbana é a escola da rua, do desconhecido, do estranho, do desconforto, diferente da escola rural, concebida, pela sua familiaridade, pela segurança, como se fosse uma casa (RIOS, 2011b). Todo esse processo produz mudanças significativas nestes jovens, que vivenciam um processo de aculturação, passando a projetar o seu futuro para fora do espaço em que sempre viveram.

Tais relatos indicam que a escola da cidade segue práticas e ritmos relacionados ao modo de vida urbano, não se importando com as múltiplas especificidades territoriais, simbólicas e subjetivas dos seus alunos, mesmo quando quase a metade desses alunos são da zona rural - $42 \%$ é o índice de alunos da zona rural no colégio pesquisado. Os professores e membros da Coordenação Pedagógica e Direção seguem, no planejamento e ações pedagógicas, a referência e lógica urbanas, e o aluno do campo é que precisa se adequar a esta realidade.

Enfim, a análise dos relatos leva-nos ao entendimento que os discursos, práticas e dispositivos do biopoder existentes na escola servem para normalizar os sujeitos, invisibilizar e negar as diferenças, apagando suas referências de vida e percepção do mundo.

\section{POR UM ENSINO MÉDIO PARA ALÉM DOS DITAMES DO MERCADO: ALGUMAS (IN)CONCLUSÕES}

Nossa intenção neste artigo foi problematizar uma temática extremamente relevante para os estudiosos interessados nas questões sobre os estudos e práticas pedagógicas voltadas para os estudantes moradores de áreas rurais: o quanto as escolas que acolhem os alunos destas regiões têm desenvolvido práticas pedagógicas ancoradas em processos de subjetivação modelizantes. (GUATTARI e ROLNIK, 1996). Ao refletirmos sobre a educação para os jovens rurais que adentram as escolas urbanas percebemos a necessidade de rompermos com esta educação pautada numa perspectiva economicista, reprodutora e castradora, cuja "[...] preocupação central é ajustar a formação humana aos imperativos do mercado [...]", como aponta Gentilli (1996, p. 22) e a de formar "[...] sujeitos 
a serviço do modo de produção capitalista no contexto da acumulação flexível do capital [...]" (MOURA, 2013, p. 6).

Concluímos que os jovens rurais chegam às escolas urbanas cheios de expectativas e anseios, buscando uma qualidade de vida melhor. O fato de frequentarem uma escola regida a partir de referências urbanas, onde suas maneiras de ser, agir e perceber o mundo são invisibilizadas e/ou negadas, gera uma intensa transformação nas suas identidades e até nos seus sonhos, pois deles exige-se que assumam uma identidade única e normalizada. O que ratifica o que pensamos a respeito da produção da subjetividade, pois a "[...] máquina capitalística produz [...] aquilo que acontece quando nós sonhamos, quando devaneamos, quando fantasiamos, [...]" (GUATTARI e ROLNIK, 1996, p. 22)

Dessa forma, observa-se que os estudantes colaboradores na pesquisa buscam o Ensino Médio, submetendo-se aos ditames do mercado, para conseguir um emprego que possa fazer com que eles consigam se projetar para fora das suas comunidades rurais, movidos pelo desejo de se inserir de forma mais intensa na sociedade do consumo. Segundo Deleuze e Guattari (1995), o desejo como produção tem a energia da invenção da realidade social. Se o desejo é a força motriz de construção da sociedade e se forma em nível inconsciente, estes jovens vão operar na construção e desconstrução de seus mundos, na metamorfose dos seus territórios existenciais. "O desejo é da ordem da produção e qualquer produção é ao mesmo tempo desejante e social" (DELEUZE E GUATTARI, 1995, p. 308).

Diante disso, observa-se o quanto a escola torna-se espaço da homogeneização, o que torna necessário repensar as práticas pedagógicas desenvolvidas, sobretudo no Ensino Médio, a fim que de que a educação para estes jovens possa ser mais acolhedora e emancipatória, ao invés de homegeneizadora e castradora. É preciso uma escola que valorize as múltiplas identidades dos sujeitos, seus modos de ser, existir e apreender a realidade para que ocorra a formação de sujeitos mais autônomos e reflexivos, tanto sobre si mesmos, como em relação aos outros e ao mundo que lhe rodeiam.

Fica evidente, então, nossa luta por uma educação mais acolhedora para estes jovens rurais, que valorize seus modos de ser e existir e não os reduzam a uma formação meramente para o mercado de trabalho. Apostamos, assim, nos estudos sobre juventudes rurais e pesquisa (auto)biográfica como forma de romper com o silêncio em torno das práticas pedagógicas que negam a identidade dos sujeitos e dos dilemas que vivenciam os alunos e alunas de áreas rurais quando ingressam nas escolas urbanas. 


\section{REFERÊNCIAS}

ANTUNES-ROCHA, Maria Isabel; HAGE, Salomão M. (Org.). Escola de direito: reinventando a escola multisseriada. Belo Horizonte: Autêntica, 2010. (Coleção Caminhos da Educação do Campo; v. 2).

AMIGUINHO, Abílio. A escola em meio rural: uma escola portadora de futuro? Revista Educação. Santa Maria, v. 33, n. 1, p. 11-32, jan./abr. 2008.

Educação e mundo rural: percursos biográficos, intervenção e pesquisa.

Educação, Sociedade \& Culturas, Porto, Portugal: CllE/Edições Afrontamentos, n. 20, p. 9-42, 2003.

BARROS, Manoel de. Livro sobre nada. Rio de Janeiro: Record, 1996.

BRASIL. Ministério da Educação - Secretária de Educação Média e Tecnológica. PCN+ Ensino Médio: Orientações Educacionais Complementares aos Parâmetros Curriculares Nacionais. Brasília: MEC; SEMTEC, 2002.

BOSI, Ecléa. Memória e Sociedade. Lembranças de Velhos. São Paulo: EDUSP, 2007.

BUENO, Belmira Oliveira. O método autobiográfico e os estudos com histórias de vida de professores: a questão da subjetividade. Educ. Pesquisa [online]. 2002, vol. 28, n.1, p. 11-30. ISSN 1678-4634. Disponível em: http://dx.doi.org/10.1590/S151797022002000100002.Acesso em 20/08/2014. Acessado em: 10.03.2017.

DAMASCENO, Maria Nobre e BESERRA, Bernadete. Estudos sobre a educação rural do Brasil: estado da arte e perspectivas. Educação e Pesquisa, São Paulo, FEUSSP, v. 30, n. 1, p.73-89, jan./abr. 2004. Disponível em:

http://www.revistas.usp.br/ep/article/view/27925/29697 Acessado em: 15.03.2017.

DANNER, Fernando. O Sentido da Biopolítica em Michel Foucault. Disponível em: http://www.ufsj.edu.br/portal2-repositorio/File/revistaestudosfilosoficos/art9-rev4.pdf. Acesso: 20/04/15.

DELEUZE, G.; GUATTARI, F. Mil Platôs: capitalismo e esquizofrenia, Vol. 1. Rio de Janeiro: Editora 34, 1995.

DELORY-MOMBERGER. A pesquisa biográfica em educação: desafios e perspectivas. In: SOUZA, Elizeu Clementino de. (Org.). Educação e ruralidades: memórias e narrativas (auto) biográficas. Salvador: EDUFBA, 2012, p. 181-200. 
FOUCAULT, Michel. Resumo dos cursos do Collége de France (1970-1982). Tradução Andréa Daher. Rio de Janeiro: Jorge Zahar, 1997.

GENTILI, Pablo. (Org.). Neoliberalismo e educação: manual do usuário. In: Escola S. A. Quem ganha e quem perde no mercado educacional do neoliberalismo. Brasília: CNTE. 1996, p. 9-49.

GUATTARI, F. Da produção de Subjetividade. In: Imagem-Máquina. PARENTE, A. (org) Rio de Janeiro, 34, 1993, p. 177-191.

GUATTARI, F.; ROLNIK, S. Micropolítica: Cartografias do Desejo. Petrópolis: Vozes, 1996.

JOSSO, Marie- Christine. Caminhar para si. Tradução Albino Pozzer, revisão Maria Helena Menna Barreto Abrahão. Porto Alegre: EDIPUCRS, 2010.

JOVCHELOVITCH, Sandra; BAUER, Martin W. Entrevista Narrativa. In: BAUER, Martin W.; GASKELL, George. Pesquisa qualitativa com texto, imagem e som: um manual prático. Tradução: Pedrinho Guareschi. 8. ed. Petrópolis, RJ: Vozes, 2010, p. 90-113.

MÉSZÁROS, István. A educação para além do capital. Tradução de Isa Tavares. São Paulo: Boitempo, 2005.

MUNARIM, A. Trajetória do movimento nacional de educação do campo no

Brasil. Revista Educação, Santa Maria, v.33, n.1, p.57-72, jan./abr. 2008. Disponível em: <http://coralx.ufsm.br/revce/revce/2008/01/a4.htm>. Acesso em: 13 set. 2010.

MOURA, Terciana Vidal. A gestão do trabalho pedagógico nas escolas do campo frente às políticas educacionais de regulação, 2013. Disponível em: http://educacaodocampopb.xpg.uol.com.br/lIEPPECPB2013/GT-\%201/2.pdf. Acesso em 10/07/2015.

NÓVOA, António; FINGER, Matthias. (Orgs.). O método (auto)biográfico e a formação. Natal: EDUFRN, São Paulo: Paulus, 2014.

NÓVOA, Antonio (Org.). Vida de professores. Porto: Editora Porto, 1992.

PASSEGGI, Maria da Conceição et al. A formação do formador na abordagem autobiográfica: a experiência dos memoriais de formação. In: Tempos, narrativas e ficções: a invenção de si. SOUZA, Elizeu Clementino de; ABRAHÃO, Maria Helena Menna Barreto, (Orgs.). Prefácio de Marie-Christine Josso, Porto Alegre: EDIPUCRS: EDUNEB, 2006, p. 203-218. 
PASSEGGI, Maria da Conceição. SOUZA, Elizeu Clementino, VICENTINI, Paula Perin. Entre a vida e a formação: pesquisa (auto) biográfica, docência e profissionalização.

Educação em Revista, v. 27, n.01, p. 369- 386, Belo Horizonte. Abr. 2011.

PINEAU, Gaston. Experiências de Aprendizagem e Histórias de vida. In: CARRÉ, Philippe; CASPAR, Pierre. Tratado das Ciências e das Técnicas da Formação. Tradução: Pedro Seixas. Lisboa: Instituto Piaget, 2000, p. 90-118. (Coleção Horizontes Pedagógicos).

RIOS, Jane Adriana Vasconcelos Pacheco. Professores da cidade, alunos da roça: identidades e discursos na escola. Revista da FAEEBA: Educação e

Contemporaneidade. Salvador: UNEB - DEDC I, v.20, n.36, jul./dez. 2011a, p. 127-136.

Ser e não ser da roça, eis a questão! Identidades e discursos na escola.

Salvador: EDUFBA, 2011b.

SANTOS, Fábio Josué Souza; SOUZA, Elizeu. Clementino de. A produção acadêmica sobre o tema Classes multisseriadas no Brasil: um olhar sobre as teses e dissertações (1987-2012) Anais... XXII EPENN, Natal-RN, out. de 2014. (GT 26).

SKLIAR, Carlos. A Educação e a pergunta pelos "Outros". Ponto de Vista, Florianópolis, n. 05, p. 37-49, 2003.

SOUZA, Elizeu Clementino de. Diálogos cruzados sobre pesquisa (auto) biográfica: análise compreensiva-interpretativa e política de sentido. Revista Educação (UFSM) 39.1, p. 39-50, 2014.

A caminho da roça: olhares, implicações e partilhas. In: SOUZA, Elizeu Clementino de. (Org.). Educação e ruralidades: memórias e narrativas (auto) biográficas. Salvador: EDUFBA, 2012, p. 17-28.

SOUZA, Elizeu Clementino de. Educação e ruralidades: olhares cruzados sobre ruralidades contemporâneas. Revista da FAEEBA: Educação e Contemporaneidade. Salvador: UNEB - DEDC I, v. 20, n.36, jul./dez. 2011, p. 15-18.

Pesquisa narrativa, (Auto)biografias e História Oral: ensino, pesquisa e formação em Educação Matemática. Ciências Humanas e Sociais em Revista (Impresso), v. 32, p. 1-14, 2010.

SOUZA, Elizeu Clementino de. (Auto)biografia, identidades e alteridade: modos de narração, escritas de si e práticas de formação na pós-graduação Ano 2, Volume 4, p. 3750 , jul-dez de 2008. 
SOUZA, Elizeu Clementino de. ORRICO, Nanci Rodrigues; SOUZA, Fábio Josué Santos. PINHO, Ana Sueli Teixeira de. Ritos de passagem de estudantes de classes multisseriadas rurais nas escolas da cidade. Roteiro, Joaçaba, v. 41, n. 1, p. 219-240, jan./abr. 2016. Disponível em: http://dx.doi.org/10.18593/r.v41i1.9269. Acesso em: 20 Set. 2017.

SCHUTZE, F. Pesquisa biográfica e entrevista narrativa. In: WELLER, V. \& PFAFF, N. (Orgs). Metodologias da pesquisa qualitativa em Educação: teoria e prática. Petrópolis: Vozes. 2010, p. 210-222.

TUAN, Yi-Fu. Espaço e lugar: a perspectiva da experiência. Tradução de Lívia de Oliveira. São Paulo: Difel, 1983.

VAN GENNEP, A. Los ritos de paso. Madrid: Alianza Editorial, 2008. 